\title{
One year later: A case study examining a community hospital's administrative response to a debris flow
}

\author{
Ann Gianola*, Steven A. Fellows \\ Santa Barbara Cottage Hospital, United States
}

Received: January 28, 2019

Accepted: March 3, 2019

Online Published: March 20, 2019

DOI: $10.5430 /$ jha.v8n2p39

URL: https://doi.org/10.5430/jha.v8n2p39

\begin{abstract}
Santa Barbara, California was first impacted by the Thomas Fire in December 2017 only to be devastated by the Montecito Debris Flow less than two weeks later. Cottage Health, a not-for-profit health system that provides advanced tertiary and quaternary medical care for patients throughout the Central Coast of California, was at the forefront of first responders to those directly impacted by the debris flow. Santa Barbara Cottage Hospital ("SBCH") (located 6 miles from the flow) treated 18 trauma patients, two first-responders, and 1 additional emergency patient later in the day, while Goleta Valley Cottage Hospital ("GVCH") (located 12 miles from the flow) treated seven patients. Flooding and debris from the storm forced the closure of Highway 101 in both directions north and south for thirteen days. Highway 101 is the only major thoroughfare from Santa Barbara to Los Angeles and forced Cottage Health to implement an internal "travel agency," in order to support Cottage Health clinicians to get to and from the two hospitals. The internal "travel agency" arranged transportation via planes, boats, vans and trains. In addition, the agency arranged accommodations utilizing local hotels, and an empty patient care unit in $\mathrm{GVCH}$. Employees and board members opened up their homes to respond to more than 4,000 transportation and 900 overnight accommodation requests. Immediately following the disaster, licensed Cottage Health clinicians implemented a How We Heal: Trauma and Anxiety Support Group series to serve all Santa Barbara residents. The series is composed of How We Heal: Process Group, How We Heal: Skill Building/Seeking Safety Group and How We Heal: Survivor Group and one year later, continues to serve the community.
\end{abstract}

Key Words: Hospital administration, Debris flow, Emergency response, Disaster management

\section{INTRODUCTION}

Santa Barbara Cottage Hospital serves as the most comprehensive tertiary and quaternary referral center and safety-net provider between Los Angeles and the Bay Area. With 510 beds, Cottage Health $(\mathrm{CH})$ is known for its widespread maternal-child and pediatric services at Cottage Children's Medical Center, cardiac, neurosurgical and oncology programs, emergency and trauma services, outpatient surgery, eye center, and inpatient and outpatient rehabilitation services at Cottage Rehabilitation Hospital. Its medical staff of more than 700 includes specialists in all major clinical areas, many of whom are involved in the training and education of new physicians in the hospital's internal medicine, general surgery and radiology residency programs.

On the evening of December 4, 2017, one of California's largest wildfires in history erupted in Ventura County. Fueled by high winds and dry vegetation, the Thomas Fire spread quickly along the California coastline. Within days, the fire spread into Santa Barbara County. The fire raged for more than 30 days and ultimately consumed 281,893 acres, including significant portions of the foothills of the Santa Ynez

\footnotetext{
*Correspondence: Ann Gianola; Email: agianola@sbch.org; Address: 400 West Pueblo St, Santa Barbara, CA 93105, Santa Barbara Cottage Hospital, United States.
}

Published by Sciedu Press 
Mountains. ${ }^{[1]}$ The Thomas Fire stripped the mountainsides of valuable soil by loosening soil, rock, and trees leaving the mountains vulnerable to debris flow. ${ }^{[2]}$

\section{INCIDENT}

Heavy rains were predicted for the recent burn areas of Santa Barbara County on Tuesday, January 9, 2018. As a result, Santa Barbara County Office of Emergency Management issued an evacuation order for residents in the hillsides above Montecito. The order was effective as of noon on January 8, 2018. ${ }^{[3]}$ However, evacuation-weary residents may have been hesitant to again load up prized possessions in their vehicles after recently returning back home after the Thomas Fire evacuations.

Around 3:30 AM Pacific Time on Tuesday, January 9, 2018, 0.54 inches of rain fell in five minutes in Montecito, California. Shortly thereafter, mudslides drove debris into the Montecito community downhill, destroying more than 128 homes and damaging 307 additional homes. ${ }^{[4]}$ The aftermath left twenty-three known dead. "Authorities fielded over 600 phone calls made to emergency dispatchers, and first responders had to use helicopters to rescue about 300 residents trapped by debris blocking the way out of the area's Romero Canyon neighborhood."[5]

The U.S. Geological Society states "Debris flows can start on steep hillsides as shallow landslides that liquefy and accelerate to speeds that are typically about $10 \mathrm{mph}$, but can exceed $35 \mathrm{mph}$. However, in recently burned areas, debris flows may also initiate from erosion on hillsides and from stream channels. The flows then reach canyon mouths or flatter ground, where the material spreads over a broad area, sometimes accumulating in thick deposits that can wreak havoc in developed areas." ${ }^{[6]}$ Because of the mudslides, U.S. Route 101, or U.S. Highway 101 (US 101) was flooded and 30 miles of the roadway closed to both north- and southbound traffic from January 9 through January 21, 2018.

\subsection{Immediate hospital response efforts}

At the time of the rainfall, the Santa Barbara Cottage Hospital (SBCH) Emergency Department (ED) had two physicians, eight registered nurses, three patient care technicians and one unit coordinator on shift. $\mathrm{SBCH}$ received its first debris flow victim at approximately 4:30 AM Pacific Time and the Tier 2 Trauma Team was activated at 4:49 AM Pacific Time. Tier 2 Trauma Team Activation (T-2 TTA) is called when patients with moderate traumatic injury or mechanism where the potential for surgery in the first few hours is considered an intermediate probability present at the ED. The activated trauma team consists of the attending ED physician, three surgical residents, ED nurses, an ED patient care technician, one respiratory therapist, one radiology technologist and one nursing supervisor. When available to assist, a trauma nurse practitioner, social services, spiritual care and radiology/CT are called. Other Tier 2 Trauma patients arrived at 5:30 AM and 5:52 AM. The Tier 1 Trauma Team was activated at 6:23 AM Pacific Time so an anesthesiologist, an operating room staff member and security were added to the already activated Tier 2 Trauma Team. The attending trauma surgeon, neurological / orthopedic consult, and the blood bank were also notified. Tier 1 Trauma Team Activation (T-1 TTA) is called when patients with severe traumatic injury or mechanism of injury in which there is a high probability of the need for immediate surgical intervention present at the ED. Overall, twenty-eight patients were treated at Cottage Health facilities. Fifteen were admitted for further evaluation, one transferred to another provider and twelve were discharged from the ED. One hundred percent of patients survived to discharge.

As the victims from the debris flow arrived by ambulance and helicopter to the ED and Level 1 Trauma Center (TC), Environmental Services deployed extra staff to those units to clean up mud and water brought into the ED. Furthermore, extra linen used to clean off patients caked in mud and debris was removed. Facilities Management scrambled to keep the facilities clean. This included stopping several rain leaks in the ED\&TC and pediatric intensive care unit (PICU) areas. The ED decontamination tanks needed to be clear in case $\mathrm{CH}$ received more victims.

$\mathrm{CH}$ developed an Emergency Operations Plan (EOP) based upon the analysis of hazards, risks and vulnerabilities to each of the hospitals and $\mathrm{CH}$ has adopted the all hazards HICS Command structure. Steven Fellows, Executive Vice President \& Chief Operating Office for Cottage Health, issued a Code Triage. This Code Triage signaled the healthcare system to respond to a natural disaster at approximately 6:00 AM Pacific Time on January 9, 2018. By 6:15 AM, the hospital incident command center (HICC) (see Figure 1) opened at Santa Barbara Cottage Hospital with Mr. Fellows assuming the role of Incident Commander. The HICC first focused on medical care for community members and then focused on assisting employees getting to and from work to ensure the medical needs of the community could be met. First reports to administrators indicated that approximately 780 employees live south of Summerland, CA and from where Highway 101 closed. These employees were unable to get to work via personal vehicles. The second priority (after providing patient care) of the HICC was to transport employees to and from Santa Barbara or Goleta Valley Cottage Hospitals. SBCH was at inpatient capacity due to an unusual flu season and GVCH was nearing capacity as well. Adult critical care 
units were full and the PICU was nearing capacity. It was essential that staff beyond the debris flow and closed Highway 101 , be able to get to work. In addition, nursing and other clinical staff would need relief after being on duty for 12 hours (see Table 1).

Table 1. Timeline of SBCH Administrative and Clinical Response

\begin{tabular}{lllll}
\hline 4:30 AM PST & 4:49 AM PST & $\mathbf{6 : 0 0}$ AM PST & $\mathbf{6 : 1 5}$ AM PST & 6:23 AM PST \\
\hline $\begin{array}{l}\text { First Debris Flow } \\
\text { Victim Arrives }\end{array}$ & $\begin{array}{l}\text { Tier 2 Trauma Team } \\
\text { Activation (T-2 TTA) }\end{array}$ & Code Triage Issued & $\begin{array}{l}\text { Hospital Incident Command } \\
\text { Center (HICC) Opened }\end{array}$ & $\begin{array}{l}\text { Tier 1 Trauma Team } \\
\text { Activation (T-1 TTA) }\end{array}$ \\
\hline & Attending ED MD & & T-2 TT PLUS \\
& 3 Residents & & Attending Trauma Surgeon \\
& ED RNs & Healthcare system & Anesthesiologist \\
& ED PCT & responds to a & Neurological/Orthopedic \\
& Respiratory Therapist & natural disaster & Consult \\
& Radiology Tech & & OR Staff Member \\
& Lab & & Security \\
& Nursing Supervisor & & Blood Bank \\
\hline
\end{tabular}

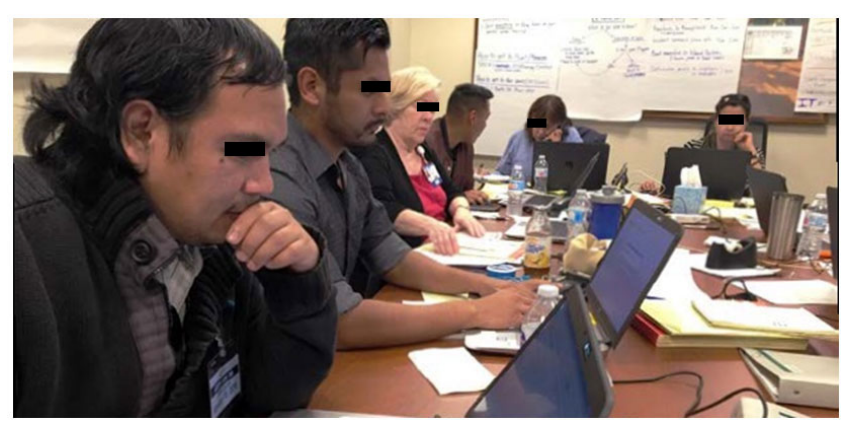

Figure 1. The hospital incident command center (HICC) at Santa Barbara Cottage Hospital

\subsection{Timeline of $\mathrm{SBCH}$ administrative and clinical re- sponse}

Coordinating a HICC can be overwhelming for some. However, $\mathrm{CH}$ has dealt with several major natural disasters in its 126-year history. This includes an earthquake, multiple fires and the loss of emergency power to its SBCH campus. The Director of Environmental Safety and Security (ESS) had two primary objectives for the first day of HICC operation: facilitate communication with community responders and support coordination of staff throughout the hospitals.

The Cottage ED\&TC, the county's Office of Emergency Management (OEM), the county's Emergency Management System (EMS), American Medical Response (AMR), the Public Health Department - County of Santa Barbara (SBCPHD), Santa Barbara City and County Fire Departments, along with the Santa Barbara Police Department work quickly and seamlessly in time of disaster and immediate human need. The ESS facilitated status updates between the organizations and provided news updates on websites and TV. When it became clear that Highway 101 was not passable and would close

Published by Sciedu Press for up to two weeks, ESS staff spoke with the Coast Guard to determine if their helicopters could be utilized to transport employees. Ultimately, Coast Guard aircraft exceeded SBCH helipad capacity (due to size and weight) so the option was discarded for other considerations.

Internally, the command center issued status updates twice per day via email. Updates occurred throughout the entire recovery period so that hospital staff and clinicians had access to up to date information. The HICC also coordinated staff from other departments (e.g., social work and mental health clinicians). Employees from other units assisted the ED\&TC with individuals coming in looking for loved ones. More specifically, a checklist was devised to begin tracking family inquiries in an effort to avoid families repeating their pleas for information. Through the Marketing Department's Public Affairs, HICC generated information needed for media briefings and external partners.

When a major highway is inaccessible and hospital staff are unable to get to work, leadership decides who is "Essential" and how to get those staff to the hospital. Hospital management quickly convened to determine who and what type of staff needed to be onsite and deemed critical for patient care. Management identified direct care providers (e.g., critical care and medical/surgical nurses, surgery nurses, technicians, Respiratory Care Practitioners [RCPs], Birth Center nurses and patient care technicians, and so on) as essential personnel. Therefore, steps were put in place to ensure those positions were filled with staff who could get to the hospital and commit to a minimum of three additional shifts. Daily, management reviewed the list of critical personnel to ensure organizational needs were met during and immediately after the event. 
The HICC managed numerous challenges brought on by a mass casualty event with road closures. It soon became clear that in addition to supporting the clinical, social, and spiritual needs of patients and families, there would be significant challenges in identifying transportation support for employees and for some of the discharged patients living outside of Santa Barbara.

The internal "travel agency", referred to as "Atlas", was set up within the command center to arrange for staff transportation via planes, trains, boats, and shuttle vans (see Figure 2). On the first day of HICC operation, the ESS director worked with Cottage Health Human Resources to establish employee transportation needs for the following day, January 10. Patient care departments had already back-filled the night shift for January 9. Shuttle vans transported staff from the Santa Barbara Airport (SBA) and Condor Express Whale Watching and Island Packers Cruises (whale watching cruise boat companies) were utilized to transport critical staff from Ventura, CA to Santa Barbara. Santa Barbara Airbus, an airport transportation company between Santa Barbara and Los Angeles International Airport, coordinated pickups from Stearns Wharf at Santa Barbara Harbor, to take staff to-and-from both SBCH and GVCH.

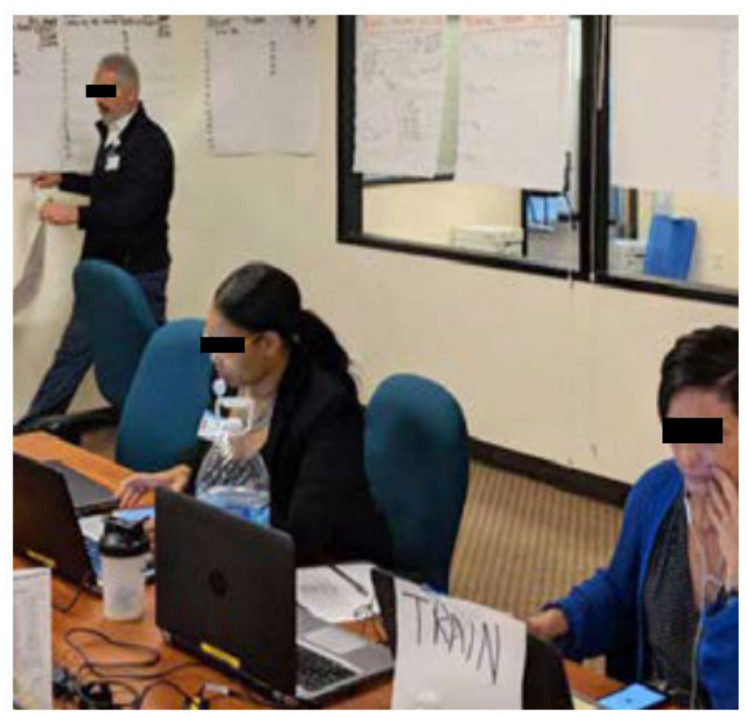

Figure 2. The newly created "travel agency" at Santa Barbara Cottage Hospital

In addition, "Atlas" secured accommodations for critical staff, utilizing local hotels, an empty patient care unit at GVCH and employee and board members' homes. Initially, the Hospitality/Concierge Services department was responsible for arranging accommodations needed for staff who were critical to the clinical operation of the facilities. Concierge staff maintained current hotel inventory and occupancy through- out the day. The employee's manager sent all staff accommodation requests to Hospitality, the requests logged onto a spreadsheet, and confirmations sent back once a hotel room was booked. Staff of "Atlas" arranged more than 900 nights of overnight housing for employees at local hotels, in patient rooms at $\mathrm{GVCH}$ and private homes. Cottage Health paid for all disaster-related costs.

The initial process for organizing the large volume of requests and coordination needs was challenging. Initial travel requests received by phone and email created a need to frequently re-print or re-assign requests to ensure they were being filled. In an effort to streamline the request process, Cottage Health's Organizational Development (OD) team utilized SurveyMonkey (www.surveymonkey.com). Realtime requests were received, edited and processed online by managers (all requests for staff transportation and overnight accommodations were coordinated through the requesting manager), and department management was able to immediately determine any gaps in staffing or resources. 3,236 staff accessed the tool to make 2,421 van ride requests, three hundred ninety-one boat ride requests, three hundred twenty train requests and one hundred four plane ride requests.

Upon the activation of a Code Triage and as defined by internal Cottage policy, resources and assets are deployed to designated areas. The Food Service Emergency Operations Plan that is mandated by Centers for Medicare \& Medicaid Services (CMS) and SBCPHD was followed according to Emergency Scenario 2 (specifically, suppliers and vendors are unable to meet CH's needs). The 101 closure resulted in supplies and food transport that normally is a two-hour drive, now took six hours longer to arrive via alternate methods. At the time of the debris flow, Cottage facilities had 488 visitors seeking food options in the hospital. The hospital would not allow external visitors because resources needed to be reserved for patients, staff and physicians caring for patients. Options for restocking supplies were unknown. Throughout the disaster, minimum food service changes occurred. Finally, elective surgeries and procedures were cancelled for only one day. All clinical services fully recovered by the third day.

\subsection{Days after}

With the date for re-opening the 101 unknown, the HICC and travel agency continued to operate at a high-level. First, $\mathrm{CH}$ requested and received road assistance from the California Highway Patrol (CHP). CHP collaborated with the Incident Commander to establish schedules, caravans and officer escorts through affected areas of Highway 101 and the debris flow of Montecito. The Director of HR \& Compensation, the first person to drive a van via CHP escort through the de- 
bris with Cottage colleagues, described the scene as horrific, unimaginable, somber and emotional. Leadership established a transportation command center staffing schedule, including temporary staff, as well as support services staff (to answer phone calls and respond to emails) that operated 24/7. The HICC also set up regular transportation needs of employees via boats and vans. This included daily pickups to-and-from $\mathrm{SBCH}$ and GVCH to the harbor for boats as well as daily pickups to-and-from $\mathrm{SBCH}$ and $\mathrm{GVCH}$ to Carpinteria and Ventura from January 11 through January 22. Twice daily communications sent to Cottage leadership and management informed them of staffing and resource needs and requests. Communication occurred between HICC, SBCPHD, and
OEM about road closures and evacuation orders.

Daily, HICC and leadership reviewed the processes for receiving and processing resource requests and staffing needs with the goal of providing timely and accurate communication to management and staff (see Figure 3). The HICC established and communicated to management the agreed upon "Direct Patient Care Providers" list for which the transportation command center would be focused on supporting. HICC maximized the utilization of the survey tool and edited the request form as needed as days progressed. Finally, HICC provided via email transportation reports to management during twice-daily briefings.

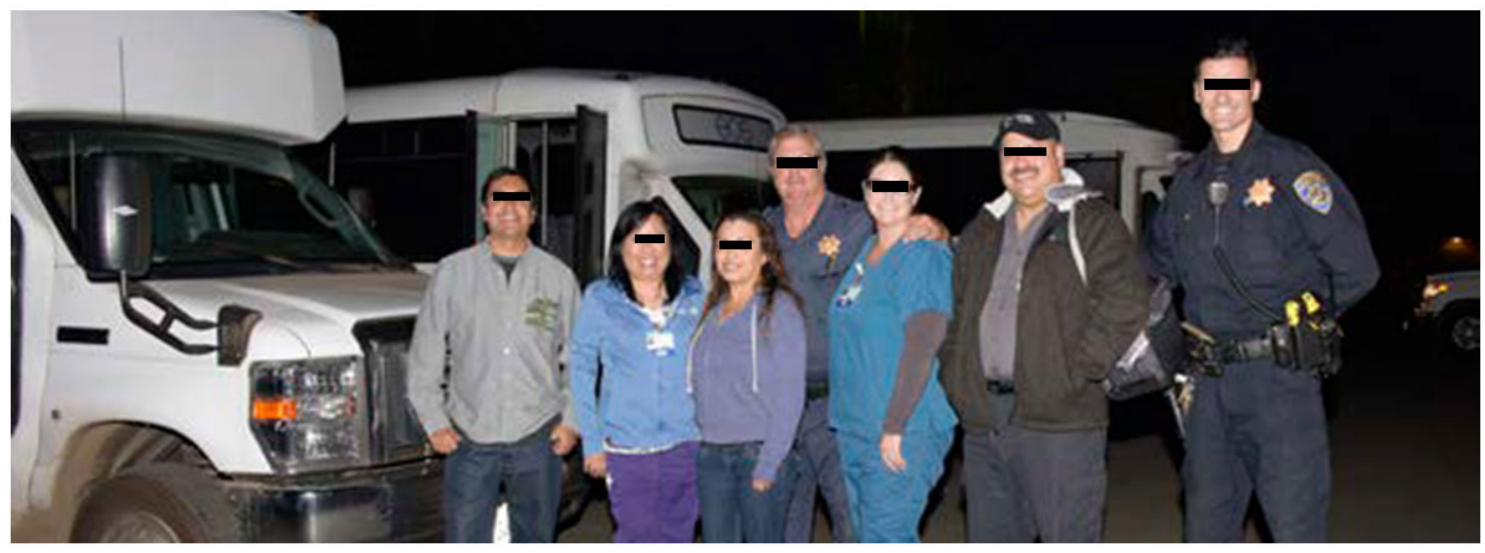

Figure 3. Cottage clinicians, California Highway Patrol, and community members working to transport Cottage Health employees through the disaster area

In addition to a clinical response, $\mathrm{CH}$ clinicians addressed spiritual, mental and emotional needs of staff, clinicians, patients and the community. Immediately following the disaster, licensed SBCH mental health clinicians implemented How We Heal: Trauma and Anxiety Support Group series to serve all Montecito and Santa Barbara residents. The series, based on the Seeking Safety curriculum, is composed of How We Heal: Process Group, How We Heal: Skill Building/Seeking Safety Group and How We Heal: Survivor Group. Immediately following the disaster, licensed clinicians held support groups four times per week and have slowly decreased to one time per week. Clinicians believe they have served more than seventy-five people and the program continues today serving those directly impacted by disaster, emergency and traumatic situations.

\subsection{Lessons learned}

On February 20, 2018, leadership held a combined debriefing for both the Thomas Fire and Montecito Mudslides. Medical Staff was represented in the debrief session and included the Director of the ED. Clinicians from Cottage Rehabilitation
Hospital (an acute rehabilitation service for patients with traumatic brain injuries, musculoskeletal and spinal cord injuries) as well as Cottage Residential Center (a residential addiction treatment center) attended. The primary areas for improvement, including recommendations for modification of the Santa Barbara Cottage Hospital Emergency Operation Plan are in Tables 2-5.

Table 2. Communication

\begin{tabular}{ll}
\hline Opportunity for Improvement & Recommended Action \\
\hline $\begin{array}{l}\text { Clearly communicating where } \\
\text { clinicians and staff need to report } \\
\text { (SBCH or GVCH) }\end{array}$ & $\begin{array}{l}\text { This information is now } \\
\text { included in emails, CAMS } \\
\text { or phone calls requesting } \\
\text { staff to report }\end{array}$ \\
\hline & $\begin{array}{l}\text { Management participates in } \\
\text { conference call ins daily to } \\
\text { ensure information is } \\
\text { received and disseminated } \\
\text { Identify who from each } \\
\text { the daily briefings }\end{array}$ \\
& $\begin{array}{l}\text { as appropriate and } \\
\text { accurately }\end{array}$ \\
\hline
\end{tabular}


Table 3. Resources and Assets

\begin{tabular}{ll}
\hline $\begin{array}{l}\text { Opportunity for } \\
\text { Improvement }\end{array}$ & Recommended Action \\
\hline $\begin{array}{l}\text { Platform or portal to view } \\
\text { travel confirmations }\end{array}$ & $\begin{array}{l}\text { IT and Marketing creating the } \\
\text { system and platform }\end{array}$ \\
$\begin{array}{l}\text { Established relationship } \\
\text { with Veterinarians to take } \\
\text { patient's pets }\end{array}$ & $\begin{array}{l}\text { Establish MOUs with local } \\
\text { veterinarians }\end{array}$ \\
& $\begin{array}{l}\text { Finance set up a dedicated cost } \\
\text { center to track costs associated with } \\
\text { Clearly document costs } \\
\text { associated with disaster } \\
\text { for FEMA reimbursement }\end{array}$ \\
$\begin{array}{l}\text { reimbursement submitted, through } \\
\text { the assistance of a consultant to } \\
\text { assure applications were complete } \\
\text { before submission }\end{array}$ \\
\hline
\end{tabular}

Table 4. Clinical Support Activities

\begin{tabular}{|c|c|}
\hline Opportunity for Improvement & Recommended Action \\
\hline $\begin{array}{l}\text { Patient tracking forms: is there } \\
\text { something within CottageOne*, } \\
\text { Cottage's clinical electronic } \\
\text { medical record, to ID them? }\end{array}$ & $\begin{array}{l}\text { Review HICS forms and } \\
\text { CottageOne to optimize } \\
\text { existing reports or modify for } \\
\text { disaster purposes }\end{array}$ \\
\hline $\begin{array}{l}\text { Extended waiting room needs a } \\
\text { mental health professional } \\
\text { present }\end{array}$ & $\begin{array}{l}\text { Dedicate a room for family } \\
\text { members or loved ones } \\
\text { looking for missing or } \\
\text { waiting. Licensed staff } \\
\text { preferable }\end{array}$ \\
\hline $\begin{array}{l}\text { Making disaster patients } \\
\text { "Confidential / No Information” } \\
\text { status for personal privacy }\end{array}$ & $\begin{array}{l}\text { Disaster patients will be } \\
\text { marked as confidential / no } \\
\text { information status }\end{array}$ \\
\hline
\end{tabular}

*CH's electronic medical record platform

Table 5. Staff Roles and Responsibilities

\begin{tabular}{ll}
\hline $\begin{array}{l}\text { Opportunity for } \\
\text { Improvement }\end{array}$ & Recommended Action \\
\hline $\begin{array}{l}\text { Education plans: How best to } \\
\text { disseminate and maintain } \\
\text { disaster education }\end{array}$ & $\begin{array}{l}\text { Evaluate options for staff } \\
\text { education and maintenance }\end{array}$ \\
\hline
\end{tabular}

\section{REFERENCES}

[1] State of California. (2019, January 3). Thomas Fire Incident Information. Available from: http://cdfdata.fire.ca.gov/incident s/incidents_details_info?incident_id=1922

[2] Thomas Burn Area Debris Flow Hazard Mapping. Available from: https://www.arcgis.com/apps/MapJournal/index.h tml?appid=541c23aa483b48978d1bc9904a6fb14d

[3] County of Santa Barbara. (2018, January 7). Announcing Winter Storm Evacuation Order and Warning Beginning Tomorrow for Parts of Santa Barbara County [Press release]. Available from: https://www. countyof sb.org/asset.c/3629
Finally, personal preparedness is emphasized at every new employee orientation. Organizational Development disseminates information related to staying informed (e.g. request emergency alerts on Santa Barbara County's Aware and Prepare website), be ready while at work, and create a disaster supplies kit.

\section{Conclusion}

On January 9, 2018, a massive debris flow triggered a multi-casualty disaster in Montecito, CA. Cottage Health responded quickly, efficiently and compassionately to provide unparalleled emergency response to the community. From well-developed internal policies to the swift implementation of the hospital incident command center, $\mathrm{CH}$ was poised to respond to the natural disaster.

The devastating January 9 debris flow is one that will forever affect the lives of friends, colleagues, neighbors and the Santa Barbara community. Reflecting on the loss of life, property and ultimate destruction from likely the most significant national event to hit the community in nearly a century, Cottage Health staff and clinicians were filled with emotion, concern and grief. In the midst of the tragedy, the level of incredible professionalism, skill, compassion, resilience and spirit was demonstrated by all, working together, saving lives, and supporting one another.

\section{ACKNOWLEDGEMENTS}

The authors wish to thank the following Cottage Health staff for their devoted administrative response to the debris flow: Susanna Shaw, Giuseppina D’Ambrosio, Nicholas Henderson, Lawrence Thomas, Ruben Cosio, Ron Lafrican, and Ruben Orozco. The authors also want to thank Cottage Health President \& CEO, Ronald Werft and other members of the administrative team for their untiring leadership and support of work outlined in this paper.

\section{CONFlicts OF INTEREST Disclosure}

The authors declare they have no conflicts of interest.
[4] County of Santa Barbara. (2018, January 18). Incident Update. Available from: https://www. countyofsb.org/asset.c/3766

[5] Patel NV. (2018, January 15). California Mudslides: 7 Maps, Pictures of the Montecito Destruction (webpage). Available from: https://www.inverse.com/article/40172-7-image $\mathrm{s}$-explain-the-california-mudslides-montecito

[6] U.S.G.S. (2018, January 26.). USGS Geologists Join Efforts in Montecito to Assess Debris-Flow Aftermath. Available from: https://www.usgs.gov/news/usgs-geologists-joi n-efforts-montecito-assess-debris-flow-aftermath 